\title{
On the Behavior of Nitrogen Oxides in the Stratosphere
}

\author{
By G. Brasseur and S. CiesLiK ${ }^{1}$ )
}

\begin{abstract}
A summary is presented of the relative importance of the principal aeronomic processes determining the vertical distribution of $\mathrm{NO}-\mathrm{NO}_{2}$ in the stratosphere. Formation and destruction of nitric oxide are considered with transport processes for steady-state conditions. Estimates of the vertical distribution of $\mathrm{NO}_{x}$ are made for extreme conditions of the eddy diffusion coefficient. It is pointed out that NO is determined by the values which are adopted for its photodissociation coefficient which is related to the absorption of solar radiation in the Schumann-Runge bands of molecular oxygen.
\end{abstract}

Nitric oxide is formed in the lower thermosphere as a result of ionospheric reactions (NORTON and BARTH [11], StRoBel et al. [13], NiCOLET [6]) and occurs in the stratosphere chiefly as a result of a reaction of the electronically excited oxygen atom $O\left({ }^{1} D\right)$ with nitrous oxide (Nicolet [7], Nicolet and Vergison [10], Nicolet and Peetermans [9], MCELRoY and MCCONNELl [5]). As far as the dissociation of nitric oxide is concerned, it has been introduced in aeronomic studies by BATES [1]. With an assumed life-time of the upper states of NO of about $10^{-6} \mathrm{sec}$, a photodissociation coefficient $J_{\mathrm{NO}}=10^{-7}$ $\mathrm{sec}^{-1}$ has been deduced at zero optical depth (BATEs [2], NiCOLET [8]) or with a transition probability of about $2 \times 10^{7} \mathrm{sec}^{-1}$, a coefficient $J_{\mathrm{NO}}=5 \times 10^{-6} \mathrm{sec}^{-1}$ (NICOLET [8]). A first investigation by STROBEL et al. [13] has led to $J_{\mathrm{NO}}=4 \times 10^{-6} \mathrm{sec}^{-1}$ while a more recent analysis by STROBEL [12] gives $J_{\mathrm{NO}} \geqslant 10^{-5} \mathrm{sec}^{-1}$.

Since the photodissociation of nitric oxide depends on various predissociation processes occurring in the $\beta, \gamma, \delta$ and $\varepsilon$-bands at $\lambda<1908 \AA$, we have used the results of CresLIK and NICOLET [4], which are based on the detailed analysis of the absorption depending on the structure of the Schumann-Runge bands of molecular oxygen. Attention will be confined here to the aeronomic conditions of nitrogen oxides in the stratosphere since a general paper by BRASSEUR and NICOLET [3] covers the subject of related chemical reactions with all references.

The one-dimensional continuity equation which is

$$
\frac{\partial n\left(\mathrm{NO}_{x}\right)}{\partial t}+\frac{\partial \Phi\left(\mathrm{NO}_{x}\right)}{\partial z}+L\left(\mathrm{NO}_{x}\right)=\mathrm{P}\left(\mathrm{NO}_{x}\right)
$$

1) Institut d'Aéronomie Spatiale de Belgique, 3 Avenue Circulaire, B-1180-Brussels, Belgium. 
where $\Phi$ is the vertical flux, $L\left(\mathrm{NO}_{x}\right)$ and $P\left(\mathrm{NO}_{x}\right)$ are respectively the loss and production rates, can be written as follows

$$
\frac{\partial n\left(\mathrm{NO}_{x}\right)}{\partial t}+\frac{\partial \Phi\left(\mathrm{NO}_{x}\right)}{\partial z}+\frac{2 J_{\mathrm{NO}} b_{6} n^{2}\left(\mathrm{NO}_{x}\right)}{R\left[b_{6} n\left(\mathrm{NO}_{x}\right)+R b_{7} n\left(\mathrm{O}_{2}\right)\right]}=2 b_{\mathrm{NO}} n\left(\mathrm{O}^{1} \mathrm{D}\right) n\left(\mathrm{~N}_{2} \mathrm{O}\right)
$$

where $n\left(\mathrm{NO}_{x}\right)=n(\mathrm{NO})+n\left(\mathrm{NO}_{2}\right)+n(\mathrm{~N})$ and $R=n\left(\mathrm{NO}_{x}\right) / n(\mathrm{NO})$.

Two reactions are particularly important. The reaction of atomic nitrogen and nitric oxide

$$
\mathrm{N}+\mathrm{NO} \rightarrow \mathrm{N}_{2}+\mathrm{O}
$$

with a rate coefficient

$$
b_{6}=2 \times 10^{-12} T^{1 / 2} \mathrm{~cm}^{3} \mathrm{sec}^{-1}
$$

and the reaction of atomic nitrogen with molecular oxygen

$$
\mathrm{N}+\mathrm{O}_{2} \rightarrow \mathrm{NO}+\mathrm{O}
$$

with a rate coefficient

$$
b_{7}=5 \times 10^{-13} T^{1 / 2} e^{-3500 / T} \mathrm{~cm}^{3} \mathrm{sec}^{-1}
$$

are the aeronomic reactions to be considered in the chemosphere.

The ratio $R=n\left(\mathrm{NO}_{x}\right) / n(\mathrm{NO})$ is practically equal to $\left[n\left(\mathrm{NO}_{2}\right)+n(\mathrm{NO})\right] / n(\mathrm{NO})$ in the stratosphere. It can be written

$$
R=1+\frac{b_{4} n\left(\mathrm{O}_{3}\right)}{J_{\mathrm{NO}_{2}}+b_{3} n(0)}
$$

where

$$
b_{4}=1 \times 10^{-12} e^{-1250 / T} \mathrm{~cm}^{-3} \mathrm{sec}^{-1}
$$

is the rate coefficient of reaction

$$
\mathrm{NO}+\mathrm{O}_{3} \rightarrow \mathrm{NO}_{2}+\mathrm{O}_{2}
$$

and

$$
b_{3}=9 \times 10^{-12} \mathrm{~cm}^{-3} \mathrm{sec}^{-1}
$$

is the rate coefficient of reaction

$$
\mathrm{O}+\mathrm{NO}_{2} \rightarrow \mathrm{NO}+\mathrm{O}_{2}
$$

The photodissociation rate of $\mathrm{NO}_{2}$ is

$$
J_{\mathrm{NO}_{2}}=9.5 \times 10^{-3} \mathrm{sec}^{-1}
$$

at zero optical depth.

The $n\left(\mathrm{NO}_{2}\right) / n(\mathrm{NO})$ ratio is given in Fig. 1 for a solar zenith angle of $60^{\circ}$ and for 
photoequilibrium conditions since the lifetime of a nitrogen dioxide molecule is short in the solar radiation field.

The principal source of odd nitrogen in the stratosphere is the reaction of the electronically excited oxygen atom $\mathrm{O}\left({ }^{1} \mathrm{D}\right)$ with nitrous oxide

$$
\mathrm{N}_{2} \mathrm{O}+\mathrm{O}\left({ }^{1} \mathrm{D}\right) \rightarrow 2 \mathrm{NO}
$$

with a rate coefficient

$$
b_{\mathrm{NO}}=10^{-10} \mathrm{~cm}^{3} \mathrm{sec}^{-1} \text {. }
$$

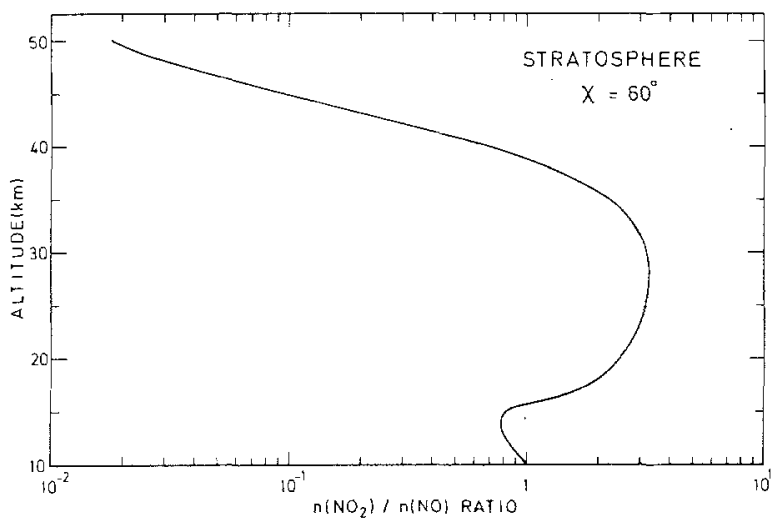

Figure 1

Ratio of the $\mathrm{NO}_{2}$ and $\mathrm{NO}$ concentration in the stratosphere calculated for a solar zenith angle of $60^{\circ}$

Additional effects such as the production of nitrogen atoms by the cosmic ray ionization (Nicolet and PeETERMans [9], W AR NECK [14]) or by a predissociation effect on $\mathrm{N}_{2}$ have not been considered here. Finally, the vertical flux of $\mathrm{NO}_{x}$ is given by

$$
\Phi=-K\left[\frac{\partial n}{\partial z}+\frac{n}{T} \frac{\partial T}{\partial z}+\frac{n}{H}\right]
$$

where $K$ is the eddy diffusion coefficient. Two analytical profiles called $K_{\max }$ and $K_{\min }$ (Fig. 2) are adopted here as extreme values (see Nicolet and Vergison [10]).

The predissociation which occurs in the $\delta$ bands is the most important process of dissociation of NO in the mesosphere and stratosphere (STROBEL [12], CIESLIK and NrCOLET [4]). Considering that the solar radiation temperature is $4800 \pm 50^{\circ} \mathrm{K}$ in the spectral region $21850-1900 \AA$, the photodissociation coefficients due to the absorption in the $\delta(0-0)$ and $\delta(1-0)$ bands are

$$
J_{\mathrm{No}}[\delta(0-0)]=(8.2 \pm 1) \times 10^{-6} \sec ^{-1}
$$

and

$$
J_{\mathrm{No}}[\delta(1-0)]=(4.5 \pm 1) \times 10^{-6} \mathrm{sec}^{-1}
$$




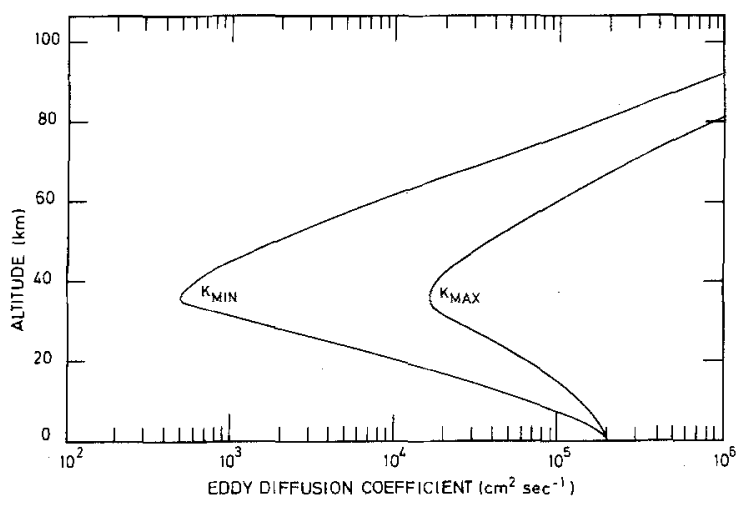

Figure 2

Adopted profiles of the eddy diffusion coefficient in the homosphere, $K_{\max }$ and $K_{\min }$

respectively (CIESLIK and NICOLET [4]). An application has been made to the mesosphere and stratosphere with the detailed rotational structure of $\mathrm{NO}$ and $\mathrm{O}_{2}$ and also with the ozone absorption in the stratosphere. The total photodissociation coefficient of NO resulting from this computation is given in Fig. 3.

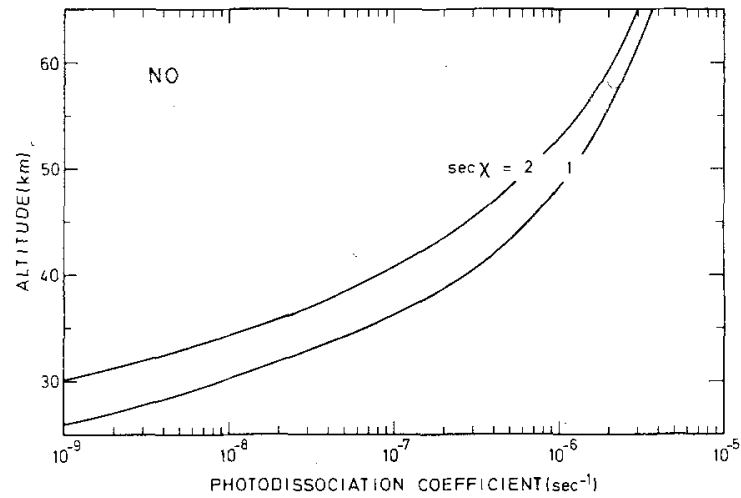

Figure 3

Photodissociation rate of NO versus altitude computed for an overhead sun and for a $60^{\circ}$ zenith angle

The nitrogen oxide distributions have been calculated in the $15-100 \mathrm{~km}$ range without considering all possible aeronomic processes but adopting special conditions which are crucially important for the present problem. A nitric oxide concentration of $10^{8}$ $\mathrm{cm}^{-3}$ has been taken as an upper boundary condition at $100 \mathrm{~km}$ with no NO production in the lower thermosphere. On the other hand, three lower boundary values have been adopted at tropopause level $(15 \mathrm{~km})$, e.g. $10^{-9}, 3 \times 10^{-9}$ and $10^{-8}$ as mixing ratio values for $\mathrm{NO}_{x}$ in order to explore the effect of varying conditions at the tropopause.

When no production process is considered in the lower thermosphere and mesosphere, it is easy to see how important the photodissociation process is. The result is 
shown in Fig. 4 where a difference of a factor of not less than 10000 is reached for the nitric oxide concentration at $60 \mathrm{~km}$ even with the high eddy diffusion coefficient $K_{\max }$.

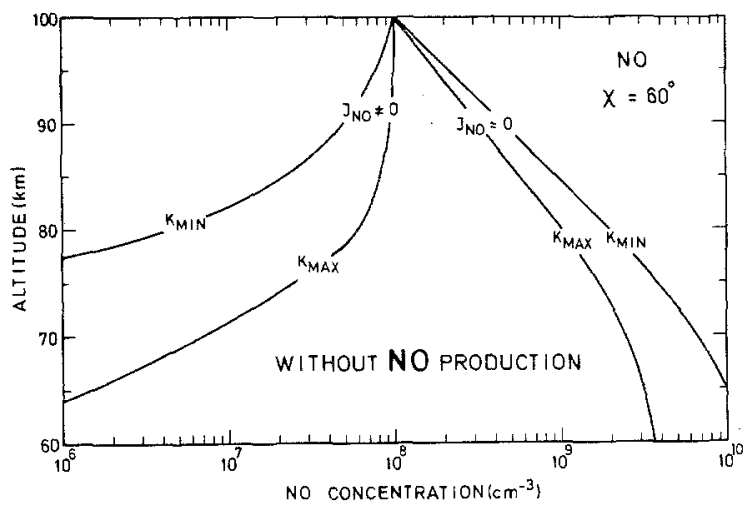

Figure 4

Effect of the photodissociation process on the NO distribution in the $60-100 \mathrm{~km}$ altitude range computed for two different eddy diffusion coefficients, $K_{\max }$ and $K_{\min }$

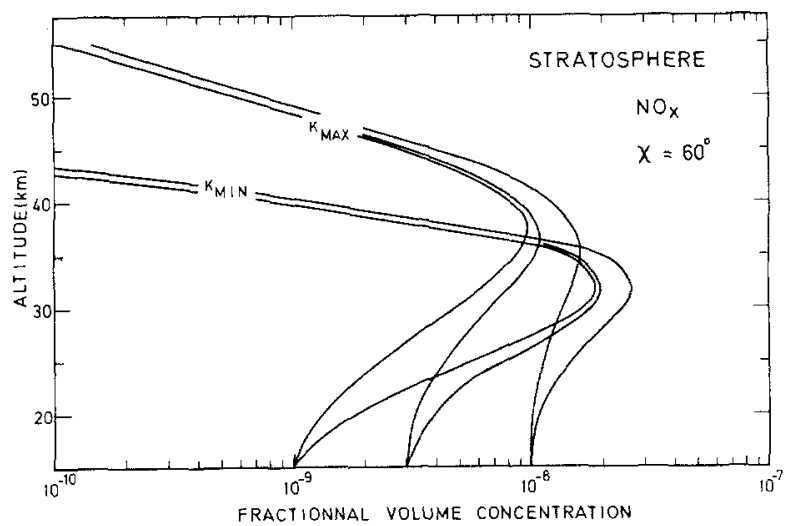

Figure 5

Fractional volume concentration of $\mathrm{NO}_{x}$ in the stratosphere for two different eddy diffusion coefficients, $K_{\max }$ and $K_{\min }$ and for three lower boundary conditions, $10^{-9}, 3 \times 10^{-9}$ and $10^{-8}$. The zenith angle is $60^{\circ}$

The vertical distribution of $\mathrm{NO}_{x}$, which is given in Fig. 5 by its volume fractional concentration, is related to the vertical production of nitric oxide (see Fig. 6) which depends on the values of the eddy diffusion coefficient. The concentration peak is controlled by the production peak of nitric oxide and is not subject to significant influence by the lower boundary conditions. Nevertheless, the absolute values of the nitrogen oxide concentrations in the lower stratosphere are sensitive to the values which are adopted at the tropopause as lower boundary conditions. The two extreme values of the eddy diffusion coefficient, $K_{\min }$ and $K_{\max }$, lead to volume fractional concentrations 


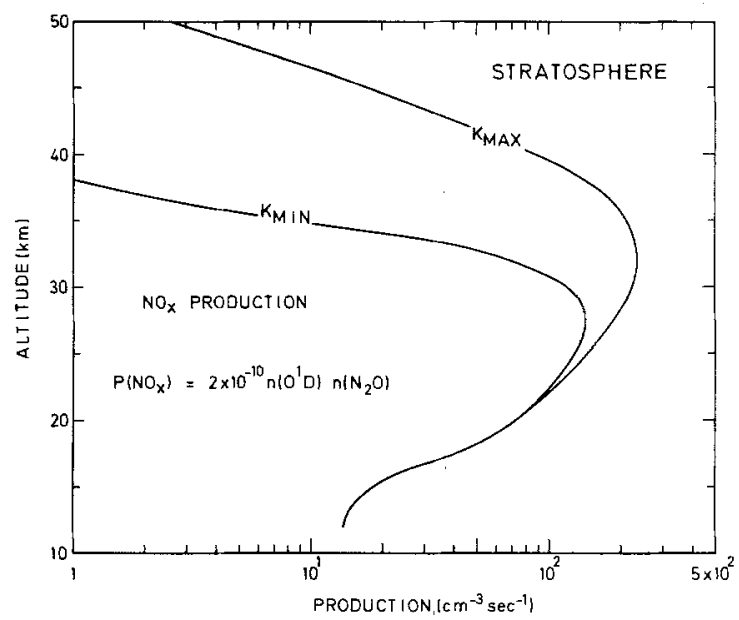

Figure 6

Example of nitrogen oxide production in the stratosphere for two different profiles of the eddy diffusion coefficient, $K_{\max }$ and $K_{\min }$ and for a sun $30^{\circ}$ above the horizon

of $2 \times 10^{-8}$ and $10^{-8}$ below and above $35 \mathrm{~km}$, respectively, when the lower boundary condition is taken as $\leqslant 3 \times 10^{-9}$. In addition the $\mathrm{NO}_{x}$ distribution near the stratopause is very sensitive to the value of the eddy diffusion coefficient as illustrated in Fig. 5 .

On the basis of our study it is possible to illustrate the behavior of the nitrogen oxide distribution by the various stratospheric fluxes of $\mathrm{NO}_{x}$ (see Fig. 7). At the mesopause

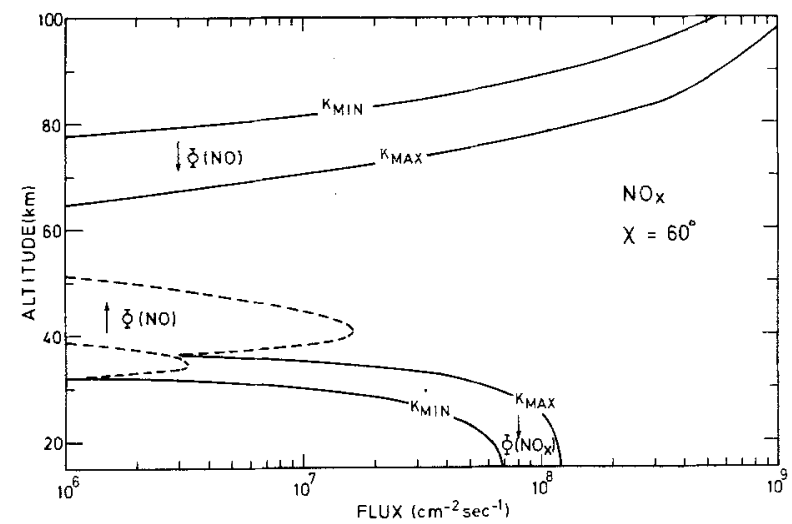

Figure 7

$\mathrm{NO}_{x}$ flux in the stratosphere and mesosphere calculated for two eddy diffusion coefficients, $K_{\text {max }}$ and $K_{\min }$. The $\mathrm{NO}_{x}$ mixing ratio was chosen to be $3 \times 10^{-9}$ at $15 \mathrm{~km}$ and the zenith angle is $60^{\circ}$. The flux is upward in the upper stratosphere and downward elsewhere

level, there is a large downward flux of NO molecules, which are destroyed in the mesosphere; the stratopause is thus much more sheltered from a downward transport of NO molecules than it was generally assumed before. The calculation shows that there is an upward transport in the upper stratosphere. Since no chemical destruction process 
has been introduced in the lower stratosphere, such as a possible effect of $\mathrm{HNO}_{3}$, for example, a downward flux of the order of $10^{8} \mathrm{~cm}^{-2} \mathrm{sec}^{-1}$ takes place at the tropopause. A more detailed analysis is required in order to determine the final sinks of nitric oxide.

\section{Acknowledgement}

The authors would like to express their gratitude to Prof. NICOLET for helpful discussions during the preparation of this work. They wish to thank Dr. KockARTs for his unpublished tables of the $\mathrm{O}_{2}$ absorption cross-sections in the Schumann-Runge bands.

\section{REFERENCES}

[1] D. R. BATES, Some reactions occurring in the Earth's upper atmosphere, Annales de Géophysique 8 (1952), 194-201.

[2] D. R. BATES, The physics of the upper atmosphere, in The Earth as a Planet, edited by G. KUTPER, Chapter 12 (The Univ. of Chicago Press 1954), pp. 576-643.

[3] G. Brasseur and M. Nicolet, to be published (1972).

[4] S. CiesLik and M. NiCOLET, to be published (1972).

[5] M. B. MCElroy and J. C. MCCONNEL, Nitrous oxide: A natural source of stratospheric NO, J. Atm. Sci. 28 (1971), 1095-1098.

[6] M. Nicolet, Nitrogen oxides in the chemosphere, J. Geophys. Res. 70 (1965), 679-689.

[7] M. NiCOLET, Aeronomic reactions of hydrogen and ozone, Aeronomica Acta A-79 (1970).

[8] M. NiCOLET, The origin of Nitric oxide in the terrestrial atmosphere, Planet. Space Sci. 18 (1970), 1111-1118.

[9] M. Nicolet and W. Peetermans, The production of nitric oxide in the stratosphere by oxidations of nitrous oxide, Annales de Géophysique (1972), to be published.

[10] M. Nicolet et E. Vergison, L'Oxyde azoteux dans la stratosphère, Aeronomica Acta A-90 (1971).

[11] R. B. NoRTon and C. A. BARTH, Theory of nitric oxide in the Earth's atmosphere, J. Geophys. Res. 75 (1970), 3903-3909.

[12] D. F. Strobel, Odd nitrogen in the mesosphere, J. Greophys. Res. 76 (1971), 8384-8393.

[13] D. F. Strobel, D. M. Hunten and M. B. MCElroy, Production and Diffusion of Nitric Oxide, J. Geophys. Res. 75 (1970), 4307-4321.

[14] P. W ARNECK, Cosmic radiation as a source of odd nitrogen in the stratosphere (1972), to be published. 